\title{
Laser Aided Ceramic Restoration Removal: A Comprehensive Review
}

\author{
Rezvaneh Ghazanfari ${ }^{1}$, Nahal Azimi ${ }^{2}$, Hanieh Nokhbatolfoghahaei ${ }^{3}{ }^{*}$, Marzieh Alikhasi ${ }^{4}$ \\ 'Department of Prosthodontics, School of Dentistry, International Campus, Tehran University of Medical Sciences, Tehran, \\ Iran \\ ${ }^{2}$ School of Dentistry, International Campus, Tehran University of Medical Sciences, Tehran, Iran \\ ${ }^{3}$ Dental Research Center, Research Institute of Dental Sciences, Shahid Beheshti University of Medical Sciences, Tehran, \\ Iran \\ ${ }^{4}$ Dental Research Center, Laser Research Center of Dentistry, Dental Implant Research center, School of Dentistry, Tehran \\ University of Medical Sciences, Tehran, Iran
}

\section{*Correspondence to Hanieh Nokhbatolfoghahaei, DDS, PhD Student; Dental Research Center, Research Institute of Dental Sciences, Shahid Beheshti University of Medical Sciences, Tehran, Iran. Department of Tissue Engineering and Applied Cell Sciences, School of Advanced Technologies in Medicine, Shahid Beheshti University of Medical Sciences, Tehran, Iran. Tel: +98-2122439847; Fax:+98-2122439847; Email: Hanieh.nokhbe@gmail.com}

Published online February 25, 2019

\begin{abstract}
Introduction: All-ceramic restorations are being widely used due to its various advantages. However, they have restricted durability and may have to be removed. The conventional procedure for removal is grinding the restoration with rotary instruments which are considered time-consuming and inconvenient. A newer advantageous method is the application of lasers for debonding ceramics from the tooth surface. The objective of this study is to provide a comprehensive literature review on laser-aided ceramic restorations debonding.

Methods: We searched PubMed and Google Scholar databases. Seven articles from 2011 to 2018 were identified. Studies were assessed for the efficacy of laser application and the amount of pulpal temperature rise.

Results: Studies selected were categorized according to variables including shear bond strength, debonding time and intrapulpal temperature. Oztoprak and Iseri investigated that erbium-doped yttrium, aluminum, and garnet (Er:YAG) laser application reduced shear bond strength of ceramic laminate veneers. The time of debonding took an average of 190 seconds in Rechmann's study and 106 seconds in Morford's study. One of the main issues while using the laser is thermal irritation of the pulp. A $5.5^{\circ} \mathrm{C}$ temperature increase may cause pulpal damage according to Zach and Cohen. Philips et al and Rechmann et al reported no intrapulpal harm due to temperature increase. Additionally, Phillips et al demonstrated that the laser setting affects both the debonding time and the temperature alterations and that a laser adjustment of $2.5 \mathrm{~W} / 25$ $\mathrm{Hz}$ would be the best safest group.

Conclusion: Removal of ceramic crowns and veneers from tooth surfaces can be successfully done by Er:YAG laser application in a less time-consuming procedure and without any harm to the underlying dentin. However, a temperature rise in the pulp may occur which could be overcome by adequate air water cooling.

Keywords: Ceramic restorations; Er:YAG laser; Restoration removal; Debonding.
\end{abstract}

\section{Introduction}

All ceramic restorations are esthetically advantageous and are increasingly used for both anterior and posterior restorations. ${ }^{1}$ Laminate veneers have many indications to improve esthetics such as discoloration, hypocalcification, peg lateral teeth, fluorosis, ${ }^{2}$ fractured teeth and diastema. ${ }^{3}$ The longevity of these restorations is limited by caries around the margins, discoloration, microleakage of the resin cement and marginal fracture of restorations. ${ }^{4}$ Under these circumstances, ceramic restorations have to be removed from tooth surfaces. The conventional removal procedure is done by grinding these restorations with rotary instruments and diamond or tungsten carbide burs. However, cutting porcelain crowns and veneers in this way is inconvenient and damages the integrity of the ceramic. As the restoration, the bonding cement and the underlying dentin have almost the same color, it takes time for the dentist to distinguish them and tooth structure may also be destroyed. In addition, diamond burs become blunt after the procedure. ${ }^{5-10}$

A number of studies have used the erbium lasers as a substitute for debonding porcelain restorations from

Please cite this article as follows: Ghazanfari R, Azimi N, Nokhbatolfoghahaei $\mathrm{H}$, Alikhasi M. Laser aided ceramic restoration removal: a comprehensive review. J Lasers Med Sci. 2019;10(2):86-91. doi:10.15171/jlms.2019.14. 
natural tooth surfaces. Erbium lasers including erbium, chromium-doped yttrium, scandium, gallium and garnet laser (Er,Cr:YSGG) and erbium-doped yttrium, aluminum, and garnet (Er:YAG) laser have an emission wavelength of $2780 \mathrm{~nm}$ and $2940 \mathrm{~nm}$ respectively which correlates with the major absorption peak of water, hydrated tissues, residual monomers and bonding cements containing water. Therefore, they are considered safe to ablate dental hard tissues (enamel, dentin). ${ }^{11}$

This method has many advantages and may be affected by several clinical factors including chemical composition and type of the ceramic, thickness of the restoration, resin cement type and shade, ceramic shade and opacity, and laser parameters such as power, pulse duration, frequency and irradiation time..$^{7,912-15}$ The aim of this study is to give a comprehensive literature review on laser-aided ceramic restoration debonding.

\section{Methods}

PubMed and Google Scholar databases were investigated for studies having the upcoming mix of keywords: "all-ceramic crown", "porcelain", "laminate", "veneer", "debonding", "crown removal", "lasers" and "intrapulpal temperature". Eight articles from 2011 to 2018 were identified. The chosen articles were in English, available in full-text format and designed to evaluate the applicability and safety of laser-aided ceramic restoration debonding. To understand the efficiency of the procedure, we focused on answering these questions:

1. "Is the laser approach effective in reducing shear bond strength and debonding time of ceramic restoration?" This was answered by 2 articles.

2. "Is the laser approach effective in reducing the debonding time?" This was answered by 4 articles. 3. "How much does the laser approach increase intrapulpal temperature?” This was answered by 2 articles.

\section{Results}

Studies selected were categorized according to variables including shear bond strength, debonding time and intrapulpal temperature. The efficiency of laser irradiation during ceramic laminate veneer removal was investigated by considering the outcome of shear bond strength. Oztoprak and Iseri showed that Er:YAG laser application reduced shear bond strength of ceramic laminate veneers. In both studies lithium disilicate glass ceramic and Variolink cement were used (Table 1). ${ }^{16,17}$

Rechmann et al applied Er:YAG laser for removal of the ceramic crown and measured debonding time. According to their study, both EmaxCAD and ZirCAD crown removal can be done effectively. An average of 120210 seconds is needed to remove the crown from standalone teeth but when arranged in an artificial natural position, it took an average of 190 seconds. This is due to the created contact points which need the angulation of the fiber. ${ }^{8}$ In Morford et al study, it took an average of
106 seconds to remove veneers from teeth. Nevertheless, the main objective of the study was to determine whether veneers could be removed without becoming destructed and the speed of debonding was less important. ${ }^{6}$ Phillips demonstrated that while pulse repetition rate remained stable in applying Er,Cr:YSGG to remove ceramic veneers, an increase in the average power resulted in a decrease in debonding time. ${ }^{18}$

One of the major concerns when using the laser for ceramic restoration debonding is the potential thermal irritation of pulp caused by laser irradiation. According to Zach and Cohen $1.8^{\circ} \mathrm{C}$, intrapulpal temperature increase causes no damage and $5.5^{\circ} \mathrm{C}$ temperature increase could cause pulp necrosis in $15 \%$ of the teeth. ${ }^{19}$ Rechmann et al ${ }^{7}$ and Philips et a $\mathrm{l}^{18}$ measured pulp temperature during laser application for veneer and crown removal respectively. In both studies, no harmful thermal increase was observed. Rechmann et al in debonding ceramic crown by Er:YAG irradiation observed that just improper use of "air/water cooling" leads to temperature increasing over $5.5^{\circ} \mathrm{C}$. To prevent thermal pulp damage, adequate cooling on the laser application side shall be done. ${ }^{7}$ Phillips showed that the increase in average power (wattage) and/or pulse repetition rate $(\mathrm{Hz})$ of the laser can result in an increase in the maximum deviation in temperature. They concluded that the laser group at $2.5 \mathrm{~W} / 25 \mathrm{~Hz}$ was the safest laser group. ${ }^{18}$

\section{Discussion}

The use of laser energy for ceramic restoration debonding requires transmission of laser energy and is absorbed by the resin cement causing degradation of cement by one of the three assumed mechanisms: thermal softening, thermal ablation and photoablation. ${ }^{20}$ These three mechanisms were first stated in the literature of "laseraided ceramic bracket removal". ${ }^{21}$

Er:YAG laser irradiation is transferred through ceramic veneers and crowns and then reacts with the bonding cement, deteriorating it, resulting in debonding and removal of the ceramic from the tooth. ${ }^{8}$

The amount of laser transmission through ceramic crowns and veneers is affected by two factors: composition and thickness of the restoration. ${ }^{6,8}$ According to Rechmann et al study, E.max CAD flat porcelain sample had the uppermost energy transmission (21\%-60\%). IPS empress esthetic (EE) transmits the energy inconsiderably lower but in the same range (21\%-49\%). However, E.max ZirCAD allows a notably less laser transmission. Therefore, E.max ZirCAD needs more extensive initial energy than the other $2.7,9$

Since zirconia does not have a stronger absorption in comparison to lithium disilicate-based on FTIR spectra at the Er:YAG laser wavelength, it is supposed that the beam scatters from the surface of zirconia. Yet, adequate energy for removal of ceramics may be transmitted through it.8 The additional energy used for ZirCAD crowns 


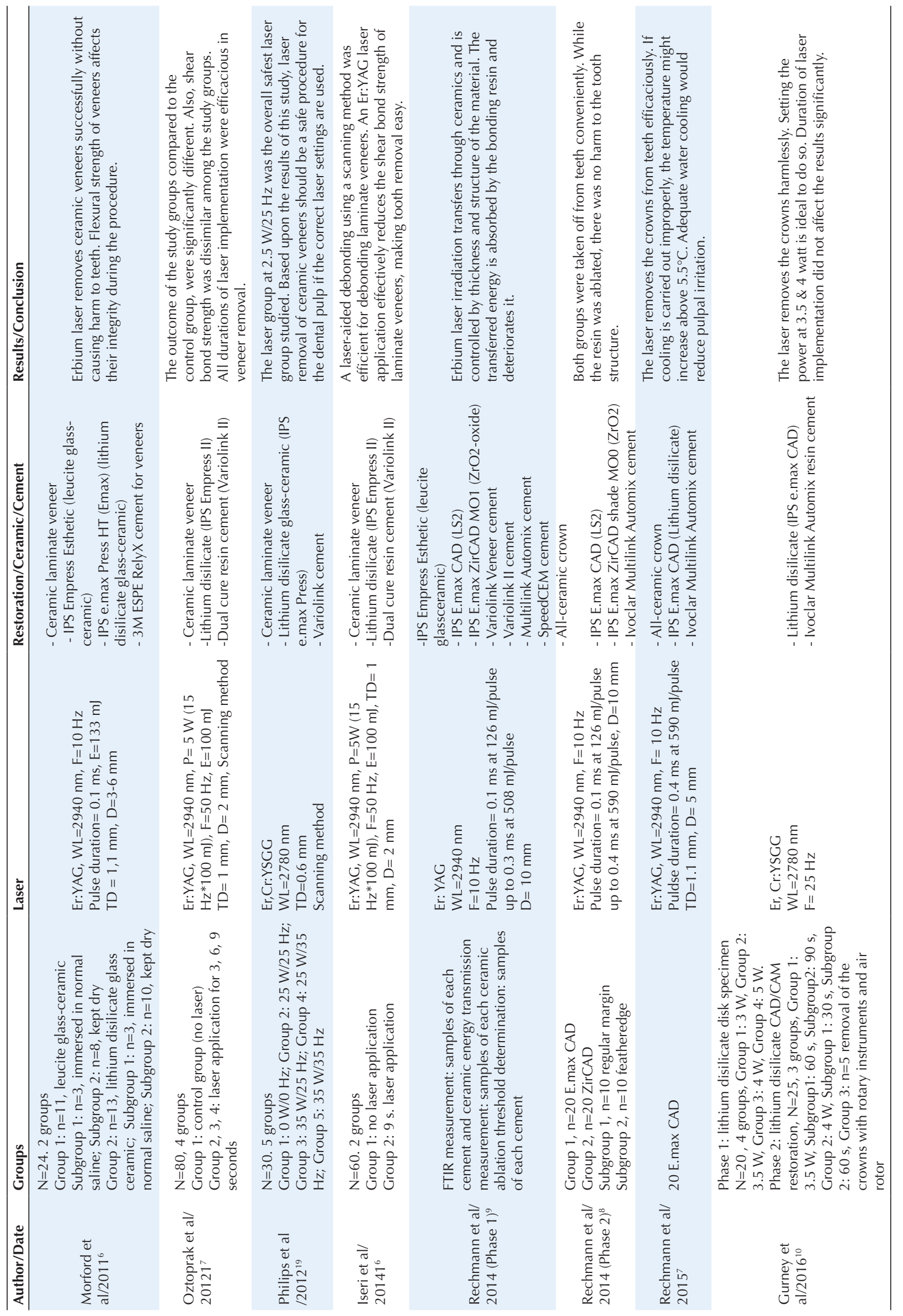


compensates the greater scattering coefficient and will not presumably raise the temperature. ${ }^{7}$ In addition, based on Morford et al study, ${ }^{6}$ EE veneers transmit approximately $12 \%-21 \%$ of the laser energy while energy transmission of IPS e.max HT veneer is twice as much (27\%-44\%). In another study, Sari et al showed that different kinds of ceramics varied in energy transmission rate. Sixty-eight percent of the laser energy passes through feldspathic ceramic of $0.5 \mathrm{~mm}$ and $88 \%$ of the energy passes through the same thickness of lithium disilicate reinforced glass ceramic. $^{22}$ Thus, material characteristics including chemical composition of ceramics and also different scattering behaviors within them will affect the amount of laser transmission. ${ }^{9}$ On the other hand, in order to deliver adequate energy to the ceramic-cement intersection, crowns with voluminous porcelain utilized in their structure, require greater energy than slim veneers to be taken away from teeth. ${ }^{6-10}$

The Er:YAG laser emits at $2940 \mathrm{~nm}$, matching with the principal peak of the water absorption spectrum. Therefore, the energy might be greatly absorbed by adhesive bonding resin compromised of water or residual monomer. ${ }^{11}$ Selecting cement with appropriate absorptive features for removing crowns, simplifies the procedure. Rechmann's phase 1 study analyzed Variolink Veneer, Variolink II, Multilink, and SpeedCEM bonding cement. They all become ablated by absorbing slight Er:YAG laser energies. However, different energies are required in order to begin fuming as the first sign of ablation. For instance, Variolink Veneer may start ablating at nearly $44 \%$ less energy than others.9 In addition, in Morford et al study, RelyX shade A1 resin displayed a wide water absorption spectrum matching with the erbium laser's spectra. Yet, it does not apply to IPS Empress Esthetic and e.max HT Press veneers. ${ }^{6}$ Cement with higher absorption features might be useful for all-ceramic crowns which transmit less laser energy such as ZirCAD crowns. ${ }^{9}$

Adjustment of laser settings affects the debonding time. Philips described an equation in this regard:

$\mathrm{J}=\mathrm{W} / \mathrm{Hz}$

Pulse Energy $(\mathrm{J})=$ Average Power $(\mathrm{W}) /$ Pulse Repetition Rate(frequency) (Hz)

A rise in the pulse frequency $(\mathrm{Hz})$ while the average power (W) stays intact, decreases the energy delivered to the bonding cement leading to a rise in the duration of the procedure. ${ }^{19}$ Moreover, greater average power levels which produce greater pulse energies will attain the ablation threshold of the bonding cement more easily causing a more rapidly debonding procedure. ${ }^{19}$

The energy used in Rechmann et al study to remove all-ceramic crowns (up to $4.7 \mathrm{~J} / \mathrm{cm}^{2}$ in phase 1 study and $2-5 \mathrm{~J} / \mathrm{cm}^{2}$ in phase 2 study) was significantly less than the energy required for dentin ablation $\left(80\right.$ to $160 \mathrm{~J} / \mathrm{cm}^{2}$ ). Also, Morford et al stated that applying low energies (energy densities of $<4.0 \mathrm{~J} / \mathrm{cm}^{2}$ ), caused no damage to the enamel since energy needed to remove veneers from teeth was much less than the energy required for ablating enamel. It may be concluded that underlying tooth structure and dental pulp would be preserved from damage. ${ }^{6,89}$ Applying air-water spray would reduce the probability of distortion and carbonization of the tooth surface. It is notable that for a short moment after initial application there is not enough cooling effect since, the laser energy penetrates through the ceramic and affects the cement-ceramic interface while air-water spray acts on the external surface of the ceramic. In the following, the water cooling's influence becomes noticeable by finding its way to the interface. ${ }^{19}$

Laser-aided ceramic restoration removal, however, poses several complications. One of the major concerns when using the laser for ceramic restoration debonding is the potential thermal irritation of pulp caused by laser irradiation. Normally, tissue temperature increases up to $45^{\circ} \mathrm{C}$, would not cause any critical organic alterations and there would be no irreversible harm to the tissue. When it rises up to $45-50^{\circ} \mathrm{C}$, enzymatic changes and edema development may be observed. A temperature exceeding $60^{\circ} \mathrm{C}$ more than a few seconds would cause coagulation including protein denaturation. ${ }^{7}$

Zach and Cohen ${ }^{19}$ in 1965 stated that an increase in temperature over $5.5^{\circ} \mathrm{C}$ results in permanent harm to the pulp based on their experiment in a monkey model. Though, Lloyd et $\mathrm{al}^{23}$ in 1986 questioned the adequacy of temperature monitoring in the study. Baldissara et $\mathrm{al}^{24}$ performed Zach and Cohen's study in human with a more accurate approach. They indicated that an average rise of $11.2^{\circ} \mathrm{C}$ would not lead to pulp pathologies and that both temperature rise and the duration of heat application determine pulpal damage. In their experiment, the pulp was heated over $43^{\circ} \mathrm{C}$ for $80-180$ seconds and there was no harm to it. In Rechmann et al study, the duration which the temperature rise was above $5.5^{\circ} \mathrm{C}$, was just 19 seconds. ${ }^{7}$ However, in Morford et al study, the temperature increasing less than $5^{\circ} \mathrm{C}$ is determined to be harmless for the pulp chamber and in Rechmann and Phillip's study, the maximum temperature rise of $5.5^{\circ} \mathrm{C}$ determined by Zach and Cohen is believed to be safe..$^{6,7}$

In Rechmann's experiment, regardless of the probable temperature increase at the interface, the temperature changes measured at the pulp chamber were averagely only $5.4^{\circ} \pm 2.2^{\circ} \mathrm{C}$. In 12 out of 20 crown removal procedures, the rise did not overreach $5.5^{\circ} \mathrm{C}$. The utmost temperature increase was reported at $11.5^{\circ} \mathrm{C}$ which occurred only in one tooth and for 15 seconds. While the change in the other 7 was $6.8 \pm 0.5^{\circ} \mathrm{C}$. No heat accumulation was observed and subsequent to the temperature rise, it decreased to 2 to $4^{\circ} \mathrm{C}$ rapidly. ${ }^{7}$

In Phillip et al study, temperature changes in all laser settings except $3.5 \mathrm{~W} / 35 \mathrm{~Hz}$ were below $5.5^{\circ} \mathrm{C}$ and considered safe. However, initial temperature settings in the study were nearly $21^{\circ} \mathrm{C}$, well below the average human body temperature of $37^{\circ} \mathrm{C} .{ }^{19}$ 
According to the mentioned equation regarding pulse energy, in a similar average power, a rise in pulse frequency increases the pulpal temperature. Although less energy is delivered per pulse, the time between peak pulse energies is decreased. Therefore, tissue will have less cooling time causing temperature elevation. 19 Also, a rise in the average power when pulse repetition rate stays the same leads to a higher energy application. This would result in a greater maximum deviation temperature and consequently an increased pulpal temperature in Phillip's study. ${ }^{19}$

Based on Rechmann's former study, the amount of water cooling and the temperature of the water affect thermal alterations in the pulp chamber. Water cooling at "below room temperature", prevents thermal accumulation and diffuses heat reducing the raised pulpal temperature. In his late experiment, he reported that temperature elevation above $5.5^{\circ} \mathrm{C}$ happened only after water cooling application at the opposing side of laser use. ${ }^{7}$

Another consideration during laser aided ceramic restoration removal is the potential risk of ceramic fracture.

In Morford et al study, an average of 36\% of Empress Esthetics veneers fractured during the debonding process most of them from those kept in saline solution for 5 days before the procedure. This is due to water absorption of porous porcelain leading to a rapid expansion of water during laser application (erbium laser irradiation has a high absorption in water) and causing cracks in veneers. Whereas, IPS e.max Press HT veneer had no fracture. Since it has a significantly higher flexural strength than the EE veneers resisting fracture and also it may have less porosity causing less water accumulation in the veneer. Flexural strength seems more important in preventing veneer cracks than any water accumulation in the veneer through the laser removal procedure. ${ }^{6}$

However, Rechmann et al stated that keeping porcelain crowns in saline for less than 21 days has no effect on crack occurrence significantly. There was very fine crack on a border of one E.max CAD crown in just a minute. 8 The benefit of veneers remaining sound after removal is in the veneer bonding appointment when positioning them in the wrong place and necessity to reposition them. ${ }^{6,9}$

\section{Conclusion}

Regarding the limitations of the current study, the use of Er:YAG laser may effectively debond and remove allceramic crowns and veneers. The debonding process could be affected by many variables such as ceramic type, ceramic thickness, resin cement composition, laser type and lasing time. Laser-aided ceramic restoration removal can be done without any change to the underlying dentin in a less time-consuming procedure. However, an increase in the pulpal temperature may be observed which can be overcome by adequate air-water cooling and adjusting the laser setting.

\section{Ethical Considerations}

Not applicable.

\section{Conflict of Interests}

The authors declare no conflict of interest.

\section{References}

1. Maheshwari P, Wagaskar V, Maheshwari R. Comparison of the efficiency and complications of lumenis and wolf morcellators after holmium laser enucleation of the prostate. Indian J Dent Res. 2011;22(1):140-3. doi: 10.4103/ iju.IJU_133_17

2. Azzaldeen A, Muhamad A-H. Restoration of esthetics using ceramics laminate veneer; clinical review: a case report. J Adv Med Dent Sci Res. 2015;3(1):1801-185.

3. Magne P, Hanna J, Magne M. The case for moderate" guided prep" indirect porcelain veneers in the anterior dentition. The pendulum of porcelain veneer preparations: from almost no-prep to over-prep to no-prep. Eur J Esthet Dent. 2013;8(3):376-388.

4. Kursoglu P, Gursoy H. Removal of fractured laminate veneers with Er: YAG laser: report of two cases. Photomed Laser Surg. 2013;31(1):41-3. doi:10.1089/pho.2012.3410

5. Nalbantgil D, Oztoprak MO, Tozlu M, Arun T. Effects of different application durations of Er: YAG laser on intrapulpal temperature change during debonding. Lasers Med Sci. 2011;26(6):735-740. doi:10.1007/s10103-0100796-7

6. Morford CK, Buu NC, Rechmann BM, Finzen FC, Sharma AB, Rechmann P. Er: YAG laser debonding of porcelain veneers. Lasers Surg Med. 2011;43(10):965-974. doi: $10.1002 / 1 \mathrm{sm} .21144$

7. Rechmann P, Buu N, Rechmann B, Finzen F. Laser allceramic crown removal and pulpal temperature-a laboratory proof-of-principle study. Lasers Med Sci. 2015;30(8):2087-2093. doi:10.1007/s10103-015-1738-1

8. Rechmann P, Buu NC, Rechmann BM, Finzen FC. Laser allceramic crown removal-a laboratory proof-of-principle study_-Phase 2 crown debonding time. Lasers Surg Med. 2014;46(8):636-643. doi:10.1002/lsm.22280

9. Rechmann P, Buu NC, Rechmann BM, Le CQ, Finzen FC, Featherstone JD. Laser all-ceramic crown removal-A laboratory proof-of-principle study-Phase 1 material characteristics. Lasers Surg Med. 2014;46(8):628-635. doi:10.1002/lsm.22279

10. Gurney ML, Sharples SD, Phillips WB, Lee DJ. Using an Er, Cr: YSGG laser to remove lithium disilicate restorations: A pilot study. J Prosthet Dent. 2016;115(1):90-4. doi:10.1016/j. prosdent.2015.08.003

11. Ghazanfari R, Nokhbatolfoghahaei H, Alikhasi M. Laseraided ceramic bracket debonding: a comprehensive review. J Lasers Med Sci. 2016;7(1):2. doi:10.15171/jlms.2016.02

12. Ekworapoj P, Sidhu SK, McCabe JF. Effect of different power parameters of Er, Cr: YSGG laser on human dentine. Lasers Med Sci. 2007;22(3):175-182. doi:10.1007/s10103006-0426-6

13. Corona SAM, Souza AE, Chinelatti MA, Borsatto MC, Pécora JD, Palma-Dibb RG. Effect of energy and pulse repetition rate of Er: YAG laser on dentin ablation ability and morphological analysis of the laser-irradiated substrate. 
Photomed Laser Ther. 2007;25(1):26-33. doi:10.1089/ pho.2006.1075

14. Corona SAM, Souza-Gabriel AE, Chinelatti MA, Pécora JD, Borsatto MC, Palma-Dibb RG. Influence of energy and pulse repetition rate of Er: YAG laser on enamel ablation ability and morphological analysis of the laser-irradiated surface. J Biomed Mater Res A. 2008;84(3):569-575. doi:10.1002/jbm.a.31335

15. Raucci-Neto W, Chinelatti MA, Palma-Dibb RG. Ablation rate and morphology of superficial and deep dentin irradiated with different Er: YAG laser energy levels. Photomed Laser Surg. 2008;26(6):523-529. doi:10.1089/ pho.2007.2201

16. Iseri U, Oztoprak MO, Ozkurt Z, Kazazoglu E, Arun T. Effect of Er: YAG laser on debonding strength of laminate veneers. Eur J Dent. 2014;8(1):58. doi:10.4103/13057456.126243

17. Oztoprak MO, Tozlu M, Iseri U, Ulkur F, Arun T. Effects of different application durations of scanning laser method on debonding strength of laminate veneers. Lasers Med Sci. 2012;27(4):713-6. doi:10.1007/s10103-011-0959-1

18. Phillips WB. Thermal changes in the dental pulp during
Er, Cr: YSGG Laser Removal of IPS e.max Press Lithium Disilicate Veneers [dissertation]. Columbus, Ohio: The Ohio State University; 2012. doi:10.1016/j.prosdent.2015.08.003

19. Zach L, Cohen G. Pulp response to externally applied heat. Oral Surg Oral Med Oral Pathol. 1965;19(4):515-530.

20. Han X, Liu X, Bai D, Meng Y, Huang L. Nd: YAG laser-aided ceramic brackets debonding: effects on shear bond strength and enamel surface. Appl Surf Sci. 2008;255(2):613-615. doi:10.1016/j.apsusc.2008.06.082

21. Tocchio RM, Williams PT, Mayer FJ, Standing KG. Laser debonding of ceramic orthodontic brackets. Am J Orthod Dentofacial Orthop. 1993;103(2):155-162. doi:10.1016/ S0889-5406(05)81765-2

22. Sari T, Tuncel I, Usumez A, Gutknecht N. Transmission of Er: YAG laser through different dental ceramics. Photomed Laser Surg. 2014;32(1):37-41. doi:10.1089/pho.2013.361116

23. Lloyd C, Joshi A, McGlynn E. Temperature rises produced by light sources and composites during curing. Dent Mater. 1986;2(4):170-4

24. Baldissara P, Catapano S, Scotti R. Clinical and histological evaluation of thermal injury thresholds in human teeth: a preliminary study. J Oral Rehabil. 1997;24(11):791-801. 